\title{
The 5, 10 methylenetetrahydrofolate reductase C677T mutation and risk of fetal loss: a case series and review of the literature Ivy Altomare*, Alan Adler and Louis M Aledort
}

\author{
Address: Mount Sinai Medical Center, 1 Gustave L. Levy Pl., New York, USA \\ Email: Ivy Altomare* - Ivy.Altomare@mssm.edu; Alan Adler - Alan.Adler@mssm.edu; Louis M Aledort - Louis.Aledort@mssm.edu \\ * Corresponding author
}

Published: 17 October 2007

Thrombosis Journal 2007, 5:17 doi:10.1186/1477-9560-5-17
Received: 29 June 2007

Accepted: 17 October 2007

This article is available from: http://www.thrombosisjournal.com/content/5///17

(C) 2007 Altomare et al; licensee BioMed Central Ltd.

This is an Open Access article distributed under the terms of the Creative Commons Attribution License (http://creativecommons.org/licenses/by/2.0), which permits unrestricted use, distribution, and reproduction in any medium, provided the original work is properly cited.

\begin{abstract}
Background: The true relationship between methylenetetrahydrofolate reductase C677T homozygosity and risk of recurrent spontaneous abortion is unknown, and it is unclear if women with these mutations should be anticoagulated during pregnancy.
\end{abstract}

Objectives: We report a series of 8 patients with this issue and review the current literature.

Methods: 8 patients ( 3 of whom were actively pregnant) were referred with histories of spontaneous fetal loss; hypercoaguability work-ups revealed each were homozygous for the MTHFR C677T mutation without other thrombophilias.

Results: In the 3 women who have conceived, treatment with LMW heparin during pregnancy led to two full-term births and one additional pregnancy without complication. For the 5 who have not, we recommended treatment with LMW heparin upon conception.

Conclusion: We provide evidence to support the relationship between MTHFR C677T mutations and recurrent fetal loss, and to suggest that anticoagulation of these patients during pregnancy can lead to a successful pregnancy outcome.

\section{Background}

There is growing evidence that thrombophilia defects can impact pregnancy outcomes. It is already well-known that the acquired thrombophilia of the antiphospholipid syndrome, seen with lupus anticoagulant and/or anticardiolipin antibody seropositivity, is strongly associated with recurrent fetal loss[1]. In the literature, various hereditary thrombophilias such as activated protein $\mathrm{C}$ resistance, the factor $\mathrm{V}$ leiden mutation (both homozygosity and heterozygosity), the prothrombin G20210A mutation, protein S deficiency, the methylenetetrahydrofolate reductase (MTHFR) C677T mutation, hyperhomocysteinemia, or combinations of the above disorders have also been linked to pregnancy loss at varying stages of gestation
$[2,3]$. Yet because many of the published case series and meta-analyses describe conflicting results, the relationship between a MTHFR mutation and recurrent miscarriages remains confusing. We present eight cases from our institution that may well represent the impact of homozygosity of the MTHFR C677T mutation on early pregnancy loss.

\section{Case series}

Eight women presented within a span of three months to our institution with histories of one or more miscarriages after the $10^{\text {th }}$ week of gestation. These women were referred to our program after their obstetricians had excluded common causes of fetal loss. None of these 
women had TORCH infections or gestational diabetes, and karyotype analyses on the products of conception (when possible) were normal. We were asked, in each case, to evaluate for thrombophilia as a cause of recurrent miscarriage and to determine if intervention (anticoagulation) would help to prevent future miscarriages. Each of these women denied a personal or family history of thrombosis.

For each patient, blood tests for both genetic and acquired causes of thrombophilia were performed (see Table 1). Pregnancy loss after the $10^{\text {th }}$ week of gestation has been more closely associated with thrombophilia, as opposed to earlier losses in weeks 3 to 9[4]. The mean age of these women was 36 years, and the number of previous miscarriages ranged from 1 to 6 . The clinical features of each case and the results of the thrombophilia work-ups are reported in Table 2. Each patient was found to be homozygous for the MTHFR C677T mutation. One patient was also heterozygous for the MTHFR A1298C mutation, three were heterozygous for the PAI-1 gene polymorphism $4 \mathrm{G} / 5 \mathrm{G}$, and one was homozygous for the PAI-1 gene polymorphism 4G/4G. Not surprisingly, homocysteine levels were in normal range for each patient, as they were each taking prenatal vitamins.

We reviewed the literature in order to find evidence to support or refute the association between MTHFR mutations and adverse pregnancy outcomes, and to guide us in managing these patients. Patients 1, 2, 3, 7 and 8 were seen hoping to become pregnant again, while patients 4 , 5 and 6 were already pregnant and not as yet anticoagulated.

\section{Table I: Hypercoaguability Profile}

\begin{tabular}{l}
\hline Fibrinogen \\
Factor VIII \\
Factor IX \\
Factor XI \\
Anti-Phosphatidyl Serine IgG \\
$\beta 2$ Glycoprotein \\
Anti-Cardiolipin IgM and IgG \\
Lupus anticoagulant \\
Plasminogen \\
Euglobulin clot lysis \\
Homocysteine \\
Factor V Leiden \\
Prothrombin G202I0A allele \\
Protein C \\
Protein S \\
Antithrombin III \\
5,I0 MTHFR gene \\
PAI-I polymorphism gene \\
Activated Protein C resistance
\end{tabular}

\section{Results}

We recommended treatment doses of low-molecular weight (LMW) heparin as a therapeutic intervention in hopes of achieving a full-term pregnancy and reducing the risk of recurrent abortion for future pregnancies. Patients 4 and 6 who were pregnant received LMW heparin immediately. Unfortunately, patient 5 miscarried prior to starting LMW heparin, but was able to conceive again and received LMW heparin shortly after this next conception. We recommended LMW heparin upon conception for patients 1, 2, 3, 7 and 8 who were not yet pregnant. As seen in Table 2, two women had successful full-term deliveries on LMW heparin, while a third woman is currently pregnant (in her third trimester) and has been taking LMW heparin since conception. Five patients are trying to conceive.

\section{Discussion}

Methyltetrahydrofolate reductase is an enzyme which catalyzes the reduction of 5, 10-methyltetrahydrofolate and allows the re-methylation of homocysteine to methionine [5]. A variant form of 5-MTHFR, termed "thermolabile" because of poor heat stability in vitro, was first described in 1988, and was found to be associated with the development of coronary artery disease. Homozygosity for the gene encoding this thermolabile mutant provides only $50 \%$ of normal MTHFR enzyme activity, and can lead to hyperhomocysteinemia [6]. Over the past two decades, multiple reports have cited the MTHFR mutation as a risk factor for both thrombosis and pregnancy loss, while others have refuted the association. Exactly how MTHFR mutations can cause pregnancy complications is unknown; a logical hypothesis is that endothelial damage from hyperhomocysteinemia leads to venous thromboemboli and placental insufficiency. In a retrospective study of 24 Indian women with recurrent pregnancy loss, the highest values of homocysteine were found in those who carried the MTHFR gene[7]. However, other reports refute this hypothesis. Another study compared homocysteine levels in 57 pregnant women with and without the MTHFR C677T mutation and found that homocysteine concentrations were not different by MTHFR genotype[8], suggesting that fetal loss associated with the MTHFR mutation can be seen in the absence of high homocysteine levels. Indeed, this is what we saw in our four patients, who are homozygous for the C677T mutation and have had several miscarriages, yet their homocysteine levels were always normal. Therefore, a different mechanism for fetal loss, less dependant on hyperhomocysteinemia, may exist.

Interestingly, patient 1 described an episode of transient spontaneous bilateral hearing loss seven years prior. Transient hearing loss can be caused by vascular insufficiency and is associated with MTHFR mutations [9]. Of note, 
Table 2: Patient Data

\begin{tabular}{|c|c|c|c|c|c|}
\hline Patient & Age & Miscarriages & Normal births & Defect & Outcome on LMW heparin \\
\hline 1 & 27 & 2 in first trimester $I$ in second trimester & I & MTHFR C677T homozygous AI298C heterozygous & N/A \\
\hline 2 & 41 & 2 in first trimester & 0 & MTHFR C677T homozygous & N/A \\
\hline 3 & 39 & 2 in first trimester & I & MTHFR C677T homozygous PAI-I heterozygous 4G/5G & Pregnancy with successful delivery \\
\hline 4 & 44 & 2 in first trimester & 0 & MTHFR C677T homozygous & Pregnancy with successful delivery \\
\hline 5 & 27 & in first trimester & 3 & MTHFR C677T homozygous PAI-I heterozygous 4G/5G & N/A \\
\hline 6 & 34 & 6 in first trimester & 3 & MTHFR C677T homozygous PAI-I heterozygous $4 \mathrm{G} / 5 \mathrm{G}$ & Pregnant, in third trimester \\
\hline 7 & 32 & 2 in first trimester & 2 & MTHFR C677T homozygous & N/A \\
\hline 8 & 40 & 3 in first trimester & 0 & MTHFR C677T homozygous PAI-I homozygous 4G/4G & N/A \\
\hline
\end{tabular}

patient \#2 is additionally heterozygous for another MTHFR mutation, A1298C, the second most common mutant polymorphism of the MTHFR mutant gene. It is estimated that $15-20 \%$ of the general population are heterozygous for one of the two variants, with prevalence even higher in certain ethnicities[10]. However, the A1298C polymorphism has never been reported as a cause of recurrent fetal loss, and has no role in causing thrombophilia [11].

MTHFR mutations have been linked to various adverse pregnancy outcomes: specifically, early fetal loss (most commonly defined as spontaneous abortion in the first or second trimester), late fetal loss (death in the third trimester), preecclampsia, intrauterine growth retardation, placental abruption and neural tube defects. We found it difficult to find clear evidence for or against the association between MTHFR mutations and the pregnancy outcomes listed above. Much of the data supporting a causative association is in the form of isolated case reports and small case series, which have been excluded from the larger meta-analyses discussed below $[2,12,13]$. Also, the definition of recurrent fetal loss varies widely among studies with respect to number of previous losses (1 to 3), the timing of losses (consecutive vs. non), and the age of gestational loss (less than 12 weeks through less than 24 weeks), making it difficult to interpret the data and compare the studies. There are a number of retrospective and case-control studies demonstrating a significantly higher frequency of MTHFR mutations in patients with recurrent fetal loss than in the control groups [14-16]. An oftencited study supporting the role of MTHFR mutations in recurrent unexplained abortions found a 2-3 fold increased risk of early fetal loss among 185 Caucasian females homozygous for the C677T mutation versus 113 normal controls[17]. These studies, combined with numerous case reports, strongly suggest a significant association between recurrent miscarriage and the mutant MTHFR allele.

Recent meta-analyses have pooled several of these and other studies, and concluded that in most cases the relationship between MTHFR mutations and adverse pregnancy outcomes is not truly significant. One meta- analysis of ten studies specifically addressing MTHFR mutations and hyperhomocysteinemia found an odds ratio of 1.4 favoring higher risk of recurrent pregnancy loss, but the confidence interval was 1.0-2.0[12]. A second meta-analysis pooled eight studies of recurrent and six of non-recurrent fetal loss, and found no association between homozygous MTHFR mutations and either clinical outcome [13]. And finally, the third and largest metaanalysis of thrombophilia in pregnancy found no association between MTHFR mutant homozygosity and venous thromboembolism or recurrent first trimester loss. There was a trend toward higher risk in the pooled analyses for non-recurrent early loss and late loss, but both confidence intervals crossed the one. This meta-analysis did find that patients with MTHFR mutant homozygosity are at increased risk of pre-ecclampsia, with a odds ratio of 1.37 reaching statistical significance [2].

Given the above data, we as clinicians are left with a dilemma of whether or not to recommend anticoagulation for patients such as these. Again, we feel that definitive evidence for or against the association of MTHFR mutations and adverse pregnancy outcomes is lacking. Admittedly, there are limitations of meta-analyses as well as the smaller positive studies. Many published case reports describe successful pregnancy outcomes with the prophylactic use of anticoagulation (most commonly low-molecular weight heparin) in women with MTHFR mutations and multiple recurrent miscarriages. However, no randomized studies exist to address the use of anticoagulation in pregnant women with MTHFR mutations. We found one study in which 351 women with recurrent miscarriages (12\% with the MTHFR mutation) were treated with prophylactic asprin + unfractionated or LMW heparin to term; the success rate of normal term delivery in this study was $94 \%$ [18].

Treatment of 3 patients with LMW heparin during pregnancy led to successful deliveries in two women, while another woman is pregnant in her third trimester with no complications thus far and is scheduled for induction. We plan to treat patients $1,2,5,7$ and 8 with LMW heparin once they become pregnant. An eighth patient with no history of fetal loss presented in consultation after a 
hypercoaguable work-up was performed prior to the planned use of hormonal agents to treat infertility (not detailed). She too is homozygous for the MTHFR mutation, in addition to being a carrier of the PAI-1 polymorphism. We recommended anticoagulation for this patient as well.

\section{Conclusion}

Although our report is also a case series, we feel it adds to the literature that the relationship between MTHFR C677T homozygosity and spontaneous abortions may be real, and we are encouraged that treatment with LMW heparin appears to have led to two successful deliveries and one uncomplicated near-complete pregnancy thus far. Only this kind of surveillance and reporting will establish whether this relationship will hold up over time.

\section{Competing interests}

The author(s) declare that they have no competing interests.

\section{References}

I. Robertson B, Greaves M: Antiphospholipid syndrome: An evolving story. Blood Rev 2006.

2. Robertson L, Wu O, Langhorne P, Twaddle S, Clark P, Lowe GD, Walker ID, Greaves M, Brenkel I, Regan L, Greer IA: Thrombophilia in pregnancy: a systematic review. Br J Haematol 2006, 132:171-196.

3. Seligsohn $U$, Lubetsky $A$ : Genetic susceptibility to venous thrombosis. N Engl J Med 200 I, 344: |222-I23I.

4. Lissalde-Lavigne G, Fabbro-Peray P, Cochery-Nouvellon E, Mercier E, Ripart-Neveu S, Balducchi JP, Daures JP, Perneger T, Quere I, Dauzat $M$, Mares P, Gris JC: Factor $\mathbf{V}$ Leiden and prothrombin G202 I OA polymorphisms as risk factors for miscarriage during a first intended pregnancy: the matched case-control 'NOHA first' study. J Thromb Haemost 2005, 3:2 I 78-2I84.

5. Kang SS, Passen EL, Ruggie N, Wong PW, Sora H: Thermolabile defect of methylenetetrahydrofolate reductase in coronary artery disease. Circulation 1993, 88: I463-I469.

6. Kang SS, Wong PW, Zhou JM, Sora J, Lessick M, Ruggie N, Grcevich G: Thermolabile methylenetetrahydrofolate reductase in patients with coronary artery disease. Metabolism 1988, 37:61I-613.

7. Kumar KS, Govindaiah V, Naushad SE, Devi RR, Jyothy A: Plasma homocysteine levels correlated to interactions between folate status and methylene tetrahydrofolate reductase gene mutation in women with unexplained recurrent pregnancy loss. J Obstet Gynaecol 2003, 23:55-58.

8. Powers RW, Dunbar MS, Gallaher MJ, Roberts JM: The 677 C-T methylenetetrahydrofolate reductase mutation does not predict increased maternal homocysteine during pregnancy. Obstet Gynecol 2003, 101:762-766.

9. Capaccio P, Ottaviani F, Cuccarini V, Ambrosetti U, Fagnani E, Bottero A, Cenzuales S, Cesana BM, Pignataro L: Methylenetetrahydrofolate reductase gene mutations as risk factors for sudden hearing loss. Am J Otolaryngol 2005, 26:383-387.

10. Hohlagschwandtner M, Unfried G, Heinze G, Huber JC, Nagele F, Tempfer C: Combined thrombophilic polymorphisms in women with idiopathic recurrent miscarriage. Fertil Steril 2003, 79: I| $4|-| \mid 48$.

II. Franco RF, Morelli V, Lourenco D, Maffei FH, Tavella MH, Piccinato $C E$, Thomazini IA, Zago MA: A second mutation in the methylenetetrahydrofolate reductase gene and the risk of venous thrombotic disease. BrJ Haematol 1999, 105:556-559.

12. Nelen WL, Blom HJ, Steegers EA, den Heijer M, Eskes TK: Hyperhomocysteinemia and recurrent early pregnancy loss: a meta-analysis. Fertil Steril 2000, 74: I I96-I I 99.
13. Rey E, Kahn SR, David M, Shrier I: Thrombophilic disorders and fetal loss: a meta-analysis. Lancet 2003, 361:901-908.

14. Lissak A, Sharon A, Fruchter O, Kassel A, Sanderovitz J, Abramovici $\mathrm{H}$ : Polymorphism for mutation of cytosine to thymine at location 677 in the methylenetetrahydrofolate reductase gene is associated with recurrent early fetal loss. Am J Obstet Gynecol 1999, 181:126-130.

15. Behjati R, Modarressi MH, Jeddi-Tehrani M, Dokoohaki P, Ghasemi J, Zarnani AH, Aarabi M, Memariani T, Ghaffari M, Akhondi MA: Thrombophilic mutations in Iranian patients with infertility and recurrent spontaneous abortion. Ann Hematol 2006, 85:268-271

16. Unfried G, Griesmacher A, Weismuller W, Nagele F, Huber JC, Tempfer CB: The C677T polymorphism of the methylenetetrahydrofolate reductase gene and idiopathic recurrent miscarriage. Obstet Gynecol 2002, 99:614-619.

17. Nelen WL, Steegers EA, Eskes TK, Blom HJ: Genetic risk factor for unexplained recurrent early pregnancy loss. Lancet 1997, 350:861.

18. Bick RL, Hoppensteadt D: Recurrent miscarriage syndrome and infertility due to blood coagulation protein/platelet defects: a review and update. Clin Appl Thromb Hemost 2005, I I: I-I3.

Publish with Biomed Central and every scientist can read your work free of charge

"BioMed Central will be the most significant development for disseminating the results of biomedical research in our lifetime. "

Sir Paul Nurse, Cancer Research UK

Your research papers will be:

- available free of charge to the entire biomedical community

- peer reviewed and published immediately upon acceptance

- cited in PubMed and archived on PubMed Central

- yours - you keep the copyright
BiolMedcentral 